\title{
A phase I dose-escalation trial of stereotactic body radiotherapy using 4 fractions for patients with localized prostate cancer
}

Takuro Kainuma', Shogo Kawakami', Hideyasu Tsumura², Takefumi Satoh², Ken-ichi Tabata², Masatsugu Iwamura², Kazushige Hayakawa' and Hiromichi Ishiyama ${ }^{1 *}$

\begin{abstract}
Purpose: To report results from our phase I dose-escalation study of stereotactic body radiotherapy (SBRT) using 4 fractions for patients with localized prostate cancer.

Materials \& methods: Fraction sizes of 8 Gy, 8.5 Gy, and 9 Gy were defined as levels 1, 2, and 3. The prescribed dose was delivered to at least $95 \%$ of the planning target volume. Image-guided, intensity-modulated radiotherapy was delivered to all patients. Dose-limiting toxicity (DLT) was defined as acute toxicity of Grade 3 or higher. The maximum tolerated dose (MTD) was defined as the level at which $\geq 30 \%$ of patients showed DLT. The recommended dose (RD) was defined to be one dose level below the MTD. If no patients at level 3 showed DLT, level 3 was defined as the recommended dose (RD).

Results: Nine patients were enrolled in each level. All patients were low or intermediate risk. Median durations of follow-up for patients at levels 1-3 were 48.9 months, 42.6 months, and 18.4 months, respectively. Protocol treatment was completed for all patients. No patient showed DLT at each dose level. Level 3 was therefore designated as the RD for the phase II study. Although most toxicities were Grade 1, genitourinary toxicity was common compared to gastrointestinal toxicity. Three-year biochemical control rate was $90.3 \%$.
\end{abstract}

Conclusion: The dose level of $36 \mathrm{~Gy}$ in 4 fractions with a 2-day break was tolerable and highly encouraging for SBRT of localized prostate cancer. The phase II trial to confirm the efficacy and toxicity of this treatment is now on going.

Trial registration: UMIN, UMIN000010236. Registered 13 March 2013.

Keywords: Prostate cancer, Stereotactic body radiotherapy, Dose-escalation

\section{Background}

The rapid advent of stereotactic body radiotherapy (SBRT) has changed our practice for treating localized prostate cancer. Most patients choose SBRT when informed about the two options of conventional intensity-modulated radiotherapy (IMRT) or SBRT, based not only on the short treatment time, but also the encouraging results.

Although the majority of reported series have used $35-37$ Gy in 5 fractions [1-3], the optimal size and

\footnotetext{
* Correspondence: hishiyam@kitasato-u.ac.jp

${ }^{1}$ Department of Radiation Oncology, Kitasato University School of Medicine,

1-15-1 Kitasato, Sagamihara, Kanagawa, Japan

Full list of author information is available at the end of the article
}

number of fractions have not yet been established for SBRT of the prostate. We started this dose-escalation trial in 2011 referring to high-dose rate brachytherapy (HDR) series using 4 fractions that had already described long-term results [4-6]. Compared to 5 fractions, we believe that our 4-fraction schedule offers several benefits.

In this study, we report results from our Phase I doseescalation study of SBRT using 4 fractions for patients with localized prostate cancer.

\section{Materials \& methods}

Eligible patients had to have histologically confirmed adenocarcinoma of the prostate with Gleason score $\leq 7$, 
initial PSA $\leq 10 \mathrm{ng} / \mathrm{ml}$, and clinical T1-T2b with neither lymph node nor distant metastases according to the UICC TNM classification version 7 . Eligibility also required that patients be $\geq 20$ years old with Eastern Cooperative Oncology Group performance status $0-1$, white-cell count $\geq 4$, $000 / \mathrm{mm}^{3}$, hemoglobin concentration $\geq 10.0 \mathrm{mg} / \mathrm{dL}$, and platelet count $\geq 100,000 / \mathrm{mm}^{3}$. Patients were excluded from this study if they met any of the following criteria: 1) history of radiotherapy, chemotherapy, or hormonal therapy; 2) deteriorated organ functions; 3) active malignancy at another site; 4) poorly controlled diabetes mellitus; 5) acute inflammatory disease; 6) cerebral stroke diagnosed with 6 months; 7) psychiatric disorder; or 8) continuous administration of steroidal drugs. Pretreatment evaluations included chest radiography, computed tomography (CT) of the abdomen and pelvis, and magnetic resonance imaging of pelvis.

Table 1 shows the dose-escalation schedule. Nine patients at each level were assigned to receive the SBRT in escalating doses. Image-guided, intensity-modulated radiotherapy using conventional linac or tomotherapy was delivered with a 2-day break (Saturday and Sunday). All patients were implanted with fiducial markers at the apex and base of the prostate before CT simulation. Clinical target volume (CTV) covered the prostate gland and proximal $1 \mathrm{~cm}$ of seminal vesicles. Planning target volume (PTV) was defined as the CTV plus 5-mm margins except posteriorly (3-mm). Prescribed dose was delivered to at least $95 \%$ of the PTV. Outer circumference of the rectum was delineated from the recto-sigmoid junction to the caudal edge of the ischium or $3 \mathrm{~cm}$ above the anal verge, whichever was lower. Outer circumferences of the bladder, femoral head, and small intestine (if it was close to the PTV), were also delineated. Dosevolume constraints for normal tissues were calculated from guidelines for conventional fractionation experiences $[7,8]$ (Table 2).

Dose-limiting toxicity (DLT) was defined as acute toxicity of at least Grade 3. The maximal tolerated dose was defined as the level at which $30 \%$ or more of patients showed DLT. If one or two of the 9 patients had DLT, the dose was escalated to the next level. If three or more patients had DLT, the dose was defined as the maximum tolerated dose (MTD). The recommended dose (RD) was defined to be one dose level below the MTD. However, if no patients at level 3 showed DLT, the level 3 was defined as the RD.

Table 1 Dose-escalation schedule

\begin{tabular}{llll}
\hline & Fraction size (Gy) & Number of fractions & Total dose (Gy) \\
\hline Level 1 & 8.0 & 4 & 32 \\
Level 2 & 8.5 & 4 & 34 \\
Level 3 & 9.0 & 4 & 36 \\
\hline
\end{tabular}

Table 2 Dose-volume constraints for normal tissues

\begin{tabular}{ll}
\hline Normal tissue dose-volume & Constraint \\
\hline Rectum & \\
V31 Gy & $25 \%$ \\
V28 Gy & $40 \%$ \\
V24 Gy & $55 \%$ \\
V20 Gy & $65 \%$ \\
Bladder & \\
V28 Gy & $30 \%$ \\
V24 Gy & $50 \%$ \\
Femoral head & \\
Maximum & $28 \mathrm{~Gy}$ \\
Small intestine & \\
Maximum & $24 \mathrm{~Gy}$ \\
\hline$V$ volume
\end{tabular}

Adverse events were evaluated according to the $\mathrm{Na}$ tional Cancer Institute's Common Terminology Criteria for Adverse Events (NCI-CTCAE) version 4.0 and Radiation Therapy Oncology Group scale [9]. In addition, the Expanded Prostate Cancer Index Composite (EPIC) [10] was used for assessment of health-related quality of life (QOL). Follow-up evaluations were performed at 1, $3,6,9$, and 12 months until 1 year after treatment, and at 6-month intervals thereafter.

\section{Results}

Nine patients were enrolled in each level. Patient characteristics are shown in Table 3. All patients were low or intermediate risk. One-third of patients received hormonal therapy for 6-22 months (median, 8.5 months). One patient with T2c and 5 patients with initial PSA > $10 \mathrm{ng} /$ $\mathrm{ml}$ (range, $12.1-17.5 \mathrm{ng} / \mathrm{ml}$ ) were included in the analysis after confirmation of acceptable minor violations. Two patients had histories of abdominal surgery (sigmoid colon cancer and gastric cancer). One patient had a history of transurethral resection of the bladder tumor. One patient had a history of holmium laser nucleation of the prostate. Median follow-up for patients at levels $1-3$ was at 48.9 months, 42.6 months, and 18.4 months, respectively.

Protocol treatment was completed for all patients. No patient experienced DLT at any dose level. As a result, level 3 was designated as the RD for the phase II study. Acute and late toxicities at each level are shown in Tables 4 and 5. Although most toxicities were Grade 1, genitourinary toxicity was common compared to gastrointestinal toxicity. One patient at level 2 had a 1-week hospital stay because of prostatitis after implantation of fiducial markers.

Three patients experienced PSA recurrence 17 months, 24 months, and 57 months after treatments. The 3 -year 
Table 3 Patient characteristics

\begin{tabular}{|c|c|c|}
\hline Variables & Values & SD \\
\hline Age (y.o.) & 71.9 & 4.74 \\
\hline iPSA (ng/mL) & 7.94 & 3.66 \\
\hline \multicolumn{3}{|l|}{ Gleason score } \\
\hline $3+3$ & 11 & \\
\hline $3+4$ & 6 & \\
\hline $4+3$ & 10 & \\
\hline \multicolumn{3}{|l|}{ T stage } \\
\hline $1 \mathrm{c}$ & 12 & \\
\hline $2 a$ & 11 & \\
\hline $2 b$ & 3 & \\
\hline $2 c$ & 1 & \\
\hline Positive cores (\%) & 32.2 & 29.3 \\
\hline \multicolumn{3}{|l|}{ Hormonal therapy } \\
\hline Yes & 10 & \\
\hline No & 17 & \\
\hline $\operatorname{CTV}\left(\mathrm{cm}^{3}\right)$ & 47.7 & 22.7 \\
\hline PTV $\left(\mathrm{cm}^{3}\right)$ & 96.9 & 35.4 \\
\hline
\end{tabular}

Abbreviations: iPSA initial prostate specific antigen, SD Standard deviation, CTV Clinical target volume, PTV Planning target volume, Values are mean or number

biochemical control rate was $90.3 \%$. One patient at level 2 showed local recurrence diagnosed by biopsy 3 years after treatment. Among the three patients with PSA recurrence, only the patient who had local recurrence received salvage hormonal therapy. Two patents died, due to pancreatic cancer and suspected duodenum tumor.

Figure 1 shows patient-reported outcomes assessed by EPIC. Regarding urinary and bowel function, drops and subsequent recovery were seen within the first 3 months after treatment. No significant difference in EPIC score was detected among the 3 dose levels.

\section{Discussion}

The 2019 guideline [11] from American Society for Radiation Oncology, the American Society for Clinical Oncology, and the American Urological Association "conditionally" recommends ultra-hypofractionated radiotherapy using 5Gy or more per fraction. However, recently published randomized control trial [12] would change the situation. Widmark et al. compared a conventional fractionation schedule (78Gy in 39 fractions) with an ultrahypofractionation schedule (42.7Gy in 7 fractions) with 1200 prostate cancer patients. There was no differences between the two-schedules regarding tumor control and late toxicity. Non-inferiority of ultra-hypofractionation to conventional fractionation was clearly demonstrated by this trial. Therefore, SBRT using $>5$ Gy per fraction would become more common in the near future.

Table 6 shows reported dose-escalation trials of SBRT for localized prostate cancer [13, 14, 15]. Because all those trials used 5 fractions [1-3], it is unsurprising that the majority of subsequent trials and current clinical practice have also used 5 fractions. We believe, however, that our 4-fraction schedule offers several benefits compared to a 5 -fraction schedule.

First, additional tumor control effects might be obtained for the same level of toxicity. Regarding late rectal toxicity, on an assumption [16] of $\alpha / \beta=5$, the schedule of $39.25 \mathrm{~Gy}$ in 5 fractions equals our $36 \mathrm{~Gy}$ in 4 fractions (equivalent dose in 2-Gy fractions: $\mathrm{EQD}=72 \mathrm{~Gy})$. However, regarding prostate cancer, and on the assumption [17] of $\alpha / \beta=1.5$, the

Table 4 Acute toxicities

\begin{tabular}{|c|c|c|c|c|c|c|c|c|c|c|c|c|}
\hline & \multicolumn{4}{|c|}{ Level $1(n=9)$} & \multicolumn{4}{|c|}{ Level $2(n=9)$} & \multicolumn{4}{|c|}{ Level $3(n=9)$} \\
\hline & \multicolumn{2}{|l|}{ G1 } & \multicolumn{2}{|c|}{ G2 } & \multicolumn{2}{|l|}{ G1 } & \multicolumn{2}{|c|}{ G2 } & \multicolumn{2}{|c|}{ G1 } & \multicolumn{2}{|l|}{ G2 } \\
\hline \multicolumn{13}{|l|}{ RTOG } \\
\hline GU & 3 & $(33.3 \%)$ & 3 & (33.3\%) & 4 & (44.4\%) & 1 & (11.1\%) & 7 & (77.8\%) & 0 & $(0.0 \%)$ \\
\hline $\mathrm{Gl}$ & 3 & $(33.3 \%)$ & 0 & $(0.0 \%)$ & 6 & $(66.7 \%)$ & 0 & $(0.0 \%)$ & 3 & (33.3\%) & 1 & (11.1\%) \\
\hline Micturition pain & 1 & $(11.1 \%)$ & 0 & $(0.0 \%)$ & 3 & (33.3\%) & 0 & $(0.0 \%)$ & 1 & (11.1\%) & 0 & $(0.0 \%)$ \\
\hline Frequency & 2 & $(22.2 \%)$ & 3 & (33.3\%) & 4 & (44.4\%) & 1 & (11.1\%) & 6 & $(66.7 \%)$ & 0 & $(0.0 \%)$ \\
\hline Urinary incontinence & 1 & $(11.1 \%)$ & 0 & $(0.0 \%)$ & 0 & $(0.0 \%)$ & 0 & $(0.0 \%)$ & 0 & $(0.0 \%)$ & 0 & $(0.0 \%)$ \\
\hline Retention & 1 & $(11.1 \%)$ & 1 & (11.1\%) & 2 & (22.2\%) & 0 & $(0.0 \%)$ & 1 & (11.1\%) & 0 & $(0.0 \%)$ \\
\hline Hematuria & 0 & $(0.0 \%)$ & 0 & $(0.0 \%)$ & 0 & $(0.0 \%)$ & 0 & $(0.0 \%)$ & 0 & $(0.0 \%)$ & 0 & $(0.0 \%)$ \\
\hline Stricture & 0 & $(0.0 \%)$ & 0 & $(0.0 \%)$ & 0 & $(0.0 \%)$ & 0 & $(0.0 \%)$ & 0 & $(0.0 \%)$ & 0 & $(0.0 \%)$ \\
\hline Proctitis & 2 & $(22.2 \%)$ & 0 & $(0.0 \%)$ & 3 & (33.3\%) & 0 & $(0.0 \%)$ & 3 & $(33.3 \%)$ & 0 & $(0.0 \%)$ \\
\hline Fecal incontinence & 0 & $(0.0 \%)$ & 0 & $(0.0 \%)$ & 0 & $(0.0 \%)$ & 0 & $(0.0 \%)$ & 0 & $(0.0 \%)$ & 0 & $(0.0 \%)$ \\
\hline Diarrhea & 1 & $(11.1 \%)$ & 0 & $(0.0 \%)$ & 3 & (33.3\%) & 0 & $(0.0 \%)$ & 0 & $(0.0 \%)$ & 0 & $(0.0 \%)$ \\
\hline Rectal hemorrhage & 1 & (11.1\%) & 0 & $(0.0 \%)$ & 4 & (44.4\%) & 0 & $(0.0 \%)$ & 1 & (11.1\%) & 1 & (11.1\%) \\
\hline
\end{tabular}


Table 5 Late toxicities

\begin{tabular}{|c|c|c|c|c|c|c|c|c|c|c|c|c|}
\hline \multirow{3}{*}{$\overline{\text { RTOG }}$} & \multicolumn{4}{|c|}{ Level $1(n=9)$} & \multicolumn{4}{|c|}{ Level $2(n=9)$} & \multicolumn{4}{|c|}{ Level $3(n=9)$} \\
\hline & \multicolumn{2}{|c|}{ G1 } & \multicolumn{2}{|c|}{ G2 } & \multicolumn{2}{|c|}{ G1 } & \multicolumn{2}{|c|}{ G2 } & \multicolumn{2}{|c|}{ G1 } & \multicolumn{2}{|l|}{ G2 } \\
\hline & & & & & & & & & & & & \\
\hline GU & 3 & (33.3\%) & 1 & $(11.1 \%)$ & 4 & $(44.4 \%)$ & 0 & $(0.0 \%)$ & 4 & $(44.4 \%)$ & 0 & $(0.0 \%)$ \\
\hline Gl & 2 & $(22.2 \%)$ & 0 & $(0.0 \%)$ & 0 & $(0.0 \%)$ & 0 & $(0.0 \%)$ & 2 & $(22.2 \%)$ & 1 & (11.1\%) \\
\hline Micturition pain & 0 & $(0.0 \%)$ & 0 & $(0.0 \%)$ & 1 & $(11.1 \%)$ & 0 & $(0.0 \%)$ & 0 & $(0.0 \%)$ & 0 & $(0.0 \%)$ \\
\hline Frequency & 4 & $(44.4 \%)$ & 0 & $(0.0 \%)$ & 4 & $(44.4 \%)$ & 0 & $(0.0 \%)$ & 4 & $(44.4 \%)$ & 0 & $(0.0 \%)$ \\
\hline Urinary incontinence & 1 & (11.1\%) & 0 & $(0.0 \%)$ & 1 & $(11.1 \%)$ & 0 & $(0.0 \%)$ & 0 & $(0.0 \%)$ & 0 & $(0.0 \%)$ \\
\hline Retention & 0 & $(0.0 \%)$ & 1 & $(11.1 \%)$ & 0 & $(0.0 \%)$ & 0 & $(0.0 \%)$ & 0 & $(0.0 \%)$ & 0 & $(0.0 \%)$ \\
\hline Hematuria & 0 & $(0.0 \%)$ & 0 & $(0.0 \%)$ & 1 & (11.1\%) & 0 & $(0.0 \%)$ & 0 & $(0.0 \%)$ & 0 & $(0.0 \%)$ \\
\hline Stricture & 0 & $(0.0 \%)$ & 0 & $(0.0 \%)$ & 0 & $(0.0 \%)$ & 0 & $(0.0 \%)$ & 0 & $(0.0 \%)$ & 0 & $(0.0 \%)$ \\
\hline Proctitis & 0 & $(0.0 \%)$ & 0 & $(0.0 \%)$ & 0 & $(0.0 \%)$ & 0 & $(0.0 \%)$ & 1 & $(11.1 \%)$ & 0 & $(0.0 \%)$ \\
\hline Fecal incontinence & 0 & $(0.0 \%)$ & 0 & $(0.0 \%)$ & 0 & $(0.0 \%)$ & 0 & $(0.0 \%)$ & 0 & $(0.0 \%)$ & 0 & $(0.0 \%)$ \\
\hline Diarrhea & 0 & $(0.0 \%)$ & 0 & $(0.0 \%)$ & 0 & $(0.0 \%)$ & 0 & $(0.0 \%)$ & 0 & $(0.0 \%)$ & 0 & $(0.0 \%)$ \\
\hline Rectal hemorrhage & 2 & $(22.2 \%)$ & 0 & $(0.0 \%)$ & 0 & $(0.0 \%)$ & 0 & $(0.0 \%)$ & 1 & (11.1\%) & 1 & (11.1\%) \\
\hline
\end{tabular}

GU Genitourinary toxicity, GI Gastrointestinal toxicity, RTOG Radiation therapy oncology group

biological effect of $39.25 \mathrm{~Gy}$ in 5 fractions (EQD = $104.8 \mathrm{~Gy})$ was lower than with our $36 \mathrm{~Gy}$ in 4 fractions $(\mathrm{EQD}=108 \mathrm{~Gy})$. The 4-fraction schedule thus provided a 3-Gy benefit for tumor control at the same level of rectal toxicity.
Second, a 4-fraction schedule showed no treatment carry-over from the previous week. For example, the number of operating weeks is 50 in the Japanese calendar for 2019. However, 11 of these 50 weeks (22\%) have only 4 operating days because of national holidays. As a result,

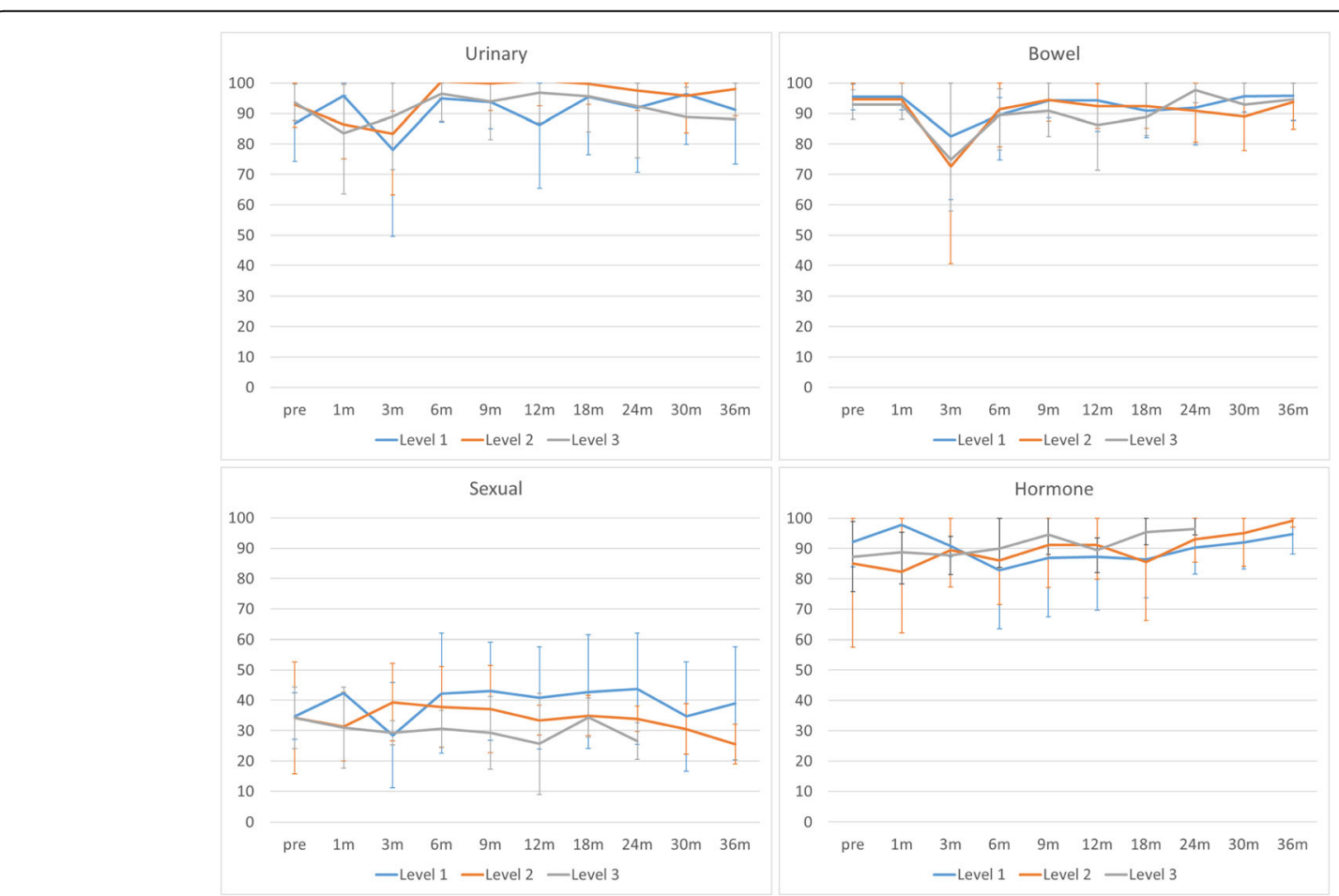

Fig. 1 Patient-reported outcomes assessed by Expanded Prostate Cancer Index Composite. A temporary drop and subsequent recovery are seen within the first 3 months after treatment regarding urinary and bowel functions. No significant differences in scores are seen among the 3 dose levels. Error bars represent standard deviations 
Table 6 Dose escalation trials for stereotactic body radiotherapy for prostate cancer patients

\begin{tabular}{|c|c|c|c|c|c|c|c|c|c|}
\hline Author & Year & $n$ & Dose and fractionation & Follow-up & Biochemical control & Acute GU & Acute Gl & Lage GU & Late Gl \\
\hline Zelefsky & 2019 & 136 & $32.5 G y-40 G y$ in $5 f x$ & $3.5-5.9$ years & 5 years: $85-100 \%$ & $\begin{array}{l}\text { G2: } 8.3-22.9 \% \\
\geq \text { G3: } 0 \%\end{array}$ & $\begin{array}{l}\text { G2: } 0-11.4 \% \\
\geq G 3: 0 \%\end{array}$ & $\begin{array}{l}\text { G2: } 23.3-31.4 \% \\
\geq G 3: 0-2.9 \%\end{array}$ & $\begin{array}{l}\text { G2: } 0 \% \\
\geq G 3: 0 \%\end{array}$ \\
\hline Hannan & 2016 & 91 & $45 G y-50 G y$ in $5 f x$ & 66-74 months & 5 years: $90.9-100 \%$ & $\begin{array}{l}\text { G2: } 6.7-33.3 \% \\
\geq \text { G3: } 0 \%\end{array}$ & $\begin{array}{l}\text { G2: } 6.7-26.7 \% \\
\geq \text { G3: } 0-3.2 \%\end{array}$ & $\begin{array}{l}\text { G2: } 19.7-26.7 \% \\
\geq G 3: 0-6.7 \%\end{array}$ & $\begin{array}{l}\text { G2: 0-18\% } \\
\geq \text { G3: } 0-9.9 \%\end{array}$ \\
\hline McBride & 2012 & 45 & 36.25Gy-37.5Gy in 5fx & 44.5 months & 3 years: 100\% & $\begin{array}{l}\text { G2: } 19 \% \\
\geq \text { G3: } 0 \%\end{array}$ & $\begin{array}{l}\text { G2: 7\% } \\
\geq \text { G3: } 0 \%\end{array}$ & $\begin{array}{l}\text { G2: } 17 \% \\
\geq G 3: 2 \%\end{array}$ & $\begin{array}{l}\text { G2: } 7 \% \\
\geq G 3: 5 \%\end{array}$ \\
\hline \multicolumn{2}{|c|}{ Present study } & 27 & 32Gy-36Gy in 4fx & 42 months & 3 years: $90.3 \%$ & $\begin{array}{l}\text { G2: } 0-33 \% \\
\geq G 3: 0 \%\end{array}$ & $\begin{array}{l}\text { G2: } 0-11 \% \\
\geq G 3: 0 \%\end{array}$ & $\begin{array}{l}\text { G2: } 0-11 \% \\
\geq G 3: 0 \%\end{array}$ & $\begin{array}{l}\text { G2: } 0-11 \% \\
\geq G 3: 0 \%\end{array}$ \\
\hline
\end{tabular}

Abbreviations: GU Genitourinary toxicity, Gl Gastrointestinal toxicity

one-fifth of patients would be carried over to the next week if a 5-fraction schedule was applied. Such carry-over increases work load and might lead to treatment errors. Our 4-fraction schedule could resolve this problem.

Third, although a difference of one fraction might be small for a single patient, the difference in total cost would not be negligible for high-volume centers such as academic institutes.

Regarding toxicity, we believe that a 2-day break has some mitigating effects. King et al. reported a significantly lower toxicity rate with a schedule of three times a week compared to a consecutive daily schedule [18]. We therefore inserted a 2-day break among the 4-fraction schedule. As our study showed, the 4-fraction schedule with a 2-day break was acceptable regarding acute and late toxicities. In addition, health-related QOL as assessed by EPIC was also acceptable under this schedule.

\section{Conclusions}

The dose level of 36 Gy in 4 fractions with a 2-day break was tolerable and highly encouraging for SBRT of localized prostate cancer. The phase II trial to confirm the efficacy and toxicity of this treatment is now on going.

\section{Abbreviations \\ CT: Computed tomography; CTV: Clinical target volume; DLT: Dose-limiting toxicity; EPIC: Expanded Prostate Cancer Index Composite; HDR: High-dose rate brachytherapy; IMRT: Intensity-modulated radiotherapy; MTD: Maximum tolerated dose; NCI-CTCAE: National Cancer Institute's Common Terminology Criteria for Adverse Events; PTV: Planning target volume; QOL: Quality of life; RD: Recommended dose; SBRT: Stereotactic body radiotherapy}

\section{Acknowledgements}

This study was supported in part by the Japanese Foundation for Multidisciplinary Treatment of Cancer.

\section{Authors' contributions}

$T K, H T, T S, K T$, and $H I$ drafted the manuscript. SK, TS and HI participated in the design of the study. HI performed the statistical analysis. MI and HK supervised the study. TK, SK, HT, TS, KT, and HI collected medical information about this study. All authors read and approved the final manuscript.

\section{Funding}

This study was supported in part by the Japanese Foundation for Multidisciplinary Treatment of Cancer.
Availability of data and materials

Data sharing not applicable to this article as no datasets were generated or analyzed during the current study.

\section{Ethics approval and consent to participate}

This study was approved by the local institutional review board (approval no. (11-703), and was registered with the University Hospital Medical Information Network (UMIN) Clinical Trials Registry (trial identifier, UMIN000010236). All patients provided written informed consent before enrollment.

\section{Consent for publication}

Written informed consent was obtained from all patients.

\section{Competing interests}

The authors declare that they have no competing interests.

\section{Author details}

'Department of Radiation Oncology, Kitasato University School of Medicine, 1-15-1 Kitasato, Sagamihara, Kanagawa, Japan. ${ }^{2}$ Department of Urology, Kitasato University School of Medicine, 1-15-1 Kitasato, Sagamihara, Kanagawa, Japan.

Received: 28 June 2019 Accepted: 22 August 2019

Published online: 02 September 2019

\section{References}

1. Alongi F, Mazzola R, Fiorentino A, et al. Phase Il study of accelerated Linacbased SBRT in five consecutive fractions for localized prostate cancer. Strahlenther Onkol. 2019;195:113.

2. Katz A. Stereotactic body radiotherapy for low-risk prostate Cancer: a tenyear analysis. Cureus. 2017;9:e1668.

3. De Bari B, Arcangeli S, Ciardo D, et al. Extreme hypofractionation for early prostate cancer: biology meets technology. Cancer Treat Rev. 2016;50:48.

4. Demanes DJ, Martinez AA, Ghilezan M, et al. High-dose-rate monotherapy: safe and effective brachytherapy for patients with localized prostate cancer. Int J Radiat Oncol Biol Phys. 2011;81:1286.

5. Ghadjar P, Keller T, Rentsch CA, et al. Toxicity and early treatment outcomes in low- and intermediate-risk prostate cancer managed by high-dose-rate brachytherapy as a monotherapy. Brachytherapy. 2009;8:45.

6. Corner C, Rojas AM, Bryant L, et al. A phase II study of high-dose-rate afterloading brachytherapy as monotherapy for the treatment of localized prostate cancer. Int J Radiat Oncol Biol Phys. 2008;72:441.

7. Martin JM, Frantzis J, Eade T, et al. Clinician's guide to prostate IMRT plan assessment and optimisation. J Med Imaging Radiat Oncol. 2010;54:569.

8. Fiorino C, Fellin G, Rancati $\mathrm{T}$, et al. Clinical and dosimetric predictors of late rectal syndrome after 3D-CRT for localized prostate cancer: preliminary results of a multicenter prospective study. Int J Radiat Oncol Biol Phys. 2008; 70:1130.

9. Cox JD, Stetz J, Pajak TF. Toxicity criteria of the radiation therapy oncology group (RTOG) and the European Organization for Research and Treatment of Cancer (EORTC). Int J Radiat Oncol Biol Phys. 1995;31:1341.

10. Kakehi $Y$, Takegami $M$, Suzukamo $Y$, et al. Health related quality of life in Japanese men with localized prostate cancer treated with current multiple 
modalities assessed by a newly developed Japanese version of the expanded prostate Cancer index composite. J Urol. 2007;177:1856.

11. Morgan SC, Hoffman K, Loblaw DA, et al. Hypofractionated radiation therapy for localized prostate Cancer: executive summary of an ASTRO, ASCO and AUA evidence-based guideline. J Urol. 2019;201:528.

12. Widmark A, Gunnlaugsson A, Beckman L, et al. Ultra-hypofractionated versus conventionally fractionated radiotherapy for prostate cancer: 5 -year outcomes of the HYPO-RT-PC randomised, non-inferiority, phase 3 trial. Lancet. 2019:394:385-95.

13. Zelefsky MJ, Kollmeier M, McBride S, et al. 5-year outcomes of a phase I dose escalation study using stereotactic body radiosurgery for patients with low and intermediate risk prostate Cancer. Int J Radiat Oncol Biol Phys. 2019;104(1):42-9.

14. Hannan R, Tumati V, Xie XJ, et al. Stereotactic body radiation therapy for low and intermediate risk prostate cancer-results from a multi-institutional clinical trial. Eur J Cancer. 2016;59:142.

15. McBride SM, Wong DS, Dombrowski JJ, et al. Hypofractionated stereotactic body radiotherapy in low-risk prostate adenocarcinoma: preliminary results of a multi-institutional phase 1 feasibility trial. Cancer. 2012;118:3681.

16. Brenner DJ. Fractionation and late rectal toxicity. Int J Radiat Oncol Biol Phys. 2004;60:1013.

17. Brenner DJ, Hall EJ. Fractionation and protraction for radiotherapy of prostate carcinoma. Int J Radiat Oncol Biol Phys. 1999;43:1095.

18. King CR, Brooks JD, Gill H, et al. Long-term outcomes from a prospective trial of stereotactic body radiotherapy for low-risk prostate cancer. Int J Radiat Oncol Biol Phys. 2012;82:877.

\section{Publisher's Note}

Springer Nature remains neutral with regard to jurisdictional claims in published maps and institutional affiliations.

Ready to submit your research? Choose BMC and benefit from:

- fast, convenient online submission

- thorough peer review by experienced researchers in your field

- rapid publication on acceptance

- support for research data, including large and complex data types

- gold Open Access which fosters wider collaboration and increased citations

- maximum visibility for your research: over $100 \mathrm{M}$ website views per year

At BMC, research is always in progress.

Learn more biomedcentral.com/submissions 